\title{
Neuroleptic Malignant Syndrome, with Attention to Its Occurrence with Atypical Antipsychotic Medication: A Review
}

\author{
Sarah Guzofski M.D. (PGY2) \\ guzofsks@ummhc.org
}

Ruben Peralta M.D.

Follow this and additional works at: https://jdc.jefferson.edu/jeffjpsychiatry

Part of the Psychiatry Commons

Let us know how access to this document benefits you

\section{Recommended Citation}

Guzofski, Sarah M.D. (PGY2) and Peralta, Ruben M.D. (2006) "Neuroleptic Malignant Syndrome, with Attention to Its Occurrence with Atypical Antipsychotic Medication: A Review," Jefferson Journal of Psychiatry. Vol. 20 : Iss. 1 , Article 7.

DOI: https://doi.org/10.29046/JJP.020.1.009

Available at: https://jdc.jefferson.edu/jeffjpsychiatry/vol20/iss1/7

This Article is brought to you for free and open access by the Jefferson Digital Commons. The Jefferson Digital Commons is a service of Thomas Jefferson University's Center for Teaching and Learning (CTL). The Commons is a showcase for Jefferson books and journals, peer-reviewed scholarly publications, unique historical collections from the University archives, and teaching tools. The Jefferson Digital Commons allows researchers and interested readers anywhere in the world to learn about and keep up to date with Jefferson scholarship. This article has been accepted for inclusion in Jefferson Journal of Psychiatry by an authorized administrator of the Jefferson Digital Commons. For more information, please contact: JeffersonDigitalCommons@jefferson.edu. 


\section{Neuroleptic Malignant Syndrome, with Attention to Its Occurrence with Atypical Antipsychotic Medication: A Review}

Sarah Guzofski, M.D. (PGY2), Ruben Peralta, M.D.

\section{ABSTRACT}

The neuroleptic malignant syndrome (NMS) is an idiopathic, life-threatening reaction to antipsychotic medication. NMS was traditionally attributed to potent dopamine antagonism of typical antipsychotics, but cases of NMS have now been reported for each of the newer antipsychotics. When NMS is caused by a newer, atypical antipsychotic the presentation differs somewhat; fever, rigidity, and, possibly, death may be less frequent. Diagnostic features, predisposing factors, and treatment are discussed, as is the important matter of reinstituting antipsychotic treatment.

Neuroleptic malignant syndrome (NMS) is an idiosyncratic, life-threatening reaction to antipsychotic medication, characterized principally by delirium, fever, autonomic instability, and muscular rigidity (1). Most cases occur within a month of starting the medication, two-thirds within the first week. NMS develops in 0.022.44 percent of patients who are prescribed antipsychotics (2-4); NMS may occur even when doses are in the therapeutic range; the risk is somewhat greater with rapid dose escalation and with parenteral administration.

Hyperthermia, delirium, autonomic instability, and extrapyramidal symptoms in a person treated with antipsychotic medications should prompt consideration of NMS. Classically, the extrapyramidal symptoms of NMS manifest as "lead pipe" rigidity of the limbs; other extrapyramidal signs, such as tremor, and cogwheeling, may be present. The muscular rigidity leads to rhabdomyolysis, which can in turn result in renal failure. A wide range of mental status presentations are possible, but patients are most often mute and stuporous. Laboratory findings include leukocytosis (most often 10-20,000, thought to be a stress response) elevated creatine kinase (can reach 100,000), hypocalcemia (from muscle sequestration of calcium), moderate elevations of LDH, AST and ALT, and elevated serum osmolarity from dehydration. An EEG may show generalized slowing, consistent with delirium (5). Symptoms generally develop over 24-72 hours and, in 
uncomplicated cases, the mean duration of symptoms is 13-15 days, longer if caused by a depot medication (2). Serious complications are possible, including renal failure, thromboembolism, respiratory failure from chest wall rigidity, aspiration pneumonia, and arrhythmia (5).

DSM IV-TR criteria (6) for diagnosing NMS are in Table 1. A slightly different set of criteria, proposed by Levenson (5), is also commonly employed (Table 2).

\section{Table 1. DSM IV-TR Diagnostic Criteria for NMS}

Severe muscle rigidity and elevated temperature associated with the use of neuroleptic medication as well as 2 or more of the following

Diaphoresis

Dysphagia

Tremor

Incontinence

Changes in level of consciousness ranging from confusion to coma

Mutism

Tachycardia

Elevated or labile blood pressure

Leukocytosis

Laboratory evidence of muscle injury

Table 2. Levenson's criteria for the diagnosis of NMS*

Major criteria

fever

rigidity

elevated creatine kinase (CK)

Minor criteria

tachycardia

abnormal blood pressure

altered consciousness

diaphoresis

leukocytosis

* 3 major criteria, or 2 major and 4 minor criteria, are required for diagnosis

In the differential diagnosis, infectious, metabolic and neurologic conditions should be considered, depending on associated clinical features (Table 3). An interesting debate has centered around the similarities and differences between malignant catatonia and NMS. These two conditions, affecting a similar patient population, can be so similar in their presenting features that some have argued 
that they are variants on a spectrum (7). Because NMS, malignant catatonia, and serotonin syndrome are difficult to distinguish on symptomatic presentation alone, medication history, behavioral prodrome, and timeline of symptom-evolution will be critical to making a diagnosis.

Table 3. Differential Diagnosis

\begin{tabular}{|l|l|}
\hline Diagnosis & Suggestive Clinical Features, Indicated Lab Testing \\
\hline $\begin{array}{l}\text { Infectious: meningitis, } \\
\text { encephalitis, bacteremic sepsis }\end{array}$ & $\begin{array}{l}\text { Lumbar puncture. Consider blood and urine cultures } \\
\text { depending on overall clinical picture }\end{array}$ \\
\hline $\begin{array}{l}\text { Metabolic: thyrotoxicosis, } \\
\text { pheochromocytoma }\end{array}$ & Check TSH, urine catacholamines and metanephrines \\
\hline $\begin{array}{l}\text { Neurologic: nonconvulsive } \\
\text { status epilepticus, postictal } \\
\text { state }\end{array}$ & EEG \\
\hline $\begin{array}{l}\text { Drug intoxications: MDMA, } \\
\text { cocaine, amphetamines }\end{array}$ & Urine toxicology \\
\hline $\begin{array}{l}\text { Serotonin syndrome } \\
\text { Lithium toxicity }\end{array}$ & $\begin{array}{l}\text { Associated with gastrointestinal signs and symptoms } \\
\text { (hyperactive bowel sounds, diarrhea, vomiting), myoclonus, } \\
\text { hyperreflexia }\end{array}$ \\
\hline $\begin{array}{l}\text { Central anticholinergic } \\
\text { syndrome }\end{array}$ & $\begin{array}{l}\text { Check lithium level. Myoclonus, hyperreflexia, tremor } \\
\text { dilated pupils }\end{array}$ \\
\hline Malignant hyperthermia & Exposure to halogenated anesthetics \\
\hline Malignant or lethal catatonia & $\begin{array}{l}\text { Associated with hyperpyrexia, rigidity, akinesia. Review } \\
\text { behavior changes over previous weeks. May be preceded } \\
\text { by emotional withdrawal, anxiety, agitation, stereotypies, } \\
\text { posturing, waxy flexibility, mutism. }\end{array}$ \\
\hline $\begin{array}{l}\text { Neuroleptic-induced heat } \\
\text { stroke }\end{array}$ & $\begin{array}{l}\text { Suggestive history: warm environment, abrupt onset, no } \\
\text { extrapyramidal signs, may have absence of diaphoresis if } \\
\text { anticholinergic properties interfere with sweating. }\end{array}$ \\
\hline
\end{tabular}

\section{Risk Factors}

NMS is an idiosyncratic reaction and cannot be predicted, but there are some identified risk factors. Young age, male gender, dehydration, agitation, rapid doseescalation, and intra-muscular administration increase the risk $(5,8)$. Prior NMS increases the risk for future episodes. There is some evidence for an association between NMS and the following $(9,10)$ : concurrent lithium treatment, poorly controlled extrapyramidal symptoms, patients with affective disorders, iron deficiency, poor nutrition, environmental heat load, catatonia, and those drugs that are more potent dopamine-2 (D2) antagonists. 


\section{Pathogenesis}

The pathogenesis of NMS is unknown. Observation that NMS occurred with D2 blocking agents lead to the hypothesis that D2 blockade in various regions of the brain explained the presentation: D2 action in the reticular activating system could cause changes in level of consciousness; D2 blockade in the nigrostriatal pathway could cause rigidity; D2 blockade in the hypothalamus could account for autonomic instability and impaired heat dissipation, thus hyperpyrexia from the combination of hypothalamic dysfunction and muscle rigidity (9-11). This theory is now challenged since atypical antipsychotics, with their lower D2 potency, are reported to cause NMS.

\section{NMS and Atypical Antipsychotics}

There have been reports of NMS attributed to each of the atypical antipsychotics and all of these medications are listed in the NMS Information Services' Registry (9). The rates and presenting symptoms of NMS in typical versus atypical antipsychotics have not been directly compared (12), but some observations are possible from available information. Of the 55 "probable" or "definite" cases of NMS reported to the Neuroleptic Malignant Syndrome Information Service between 1998 and 2002, 31 patients (56\%) were on a typical antipsychotic; 24 patients (44\%) were on an atypical antipsychotic (13). Cases of NMS have been reported with even the least potent D2 antagonist, clozapine $(2,14)$.

NMS owing to atypical antipsychotics has possibly a different presentation compared with the traditional syndrome: less extreme $\mathrm{CK}$ and temperature elevations and less common and milder rigidity (14,15). A 2003 review of 68 reported cases of NMS from atypical antipsychotics found that the mean peak CK was 5958 and the mean maximum temperature was 38.8. Seventy eight percent of patients had extrapyramidal symptoms. Twelve of the 68 required intensive care and 3 patients died (2). This mortality rate is less than that historically reported in NMS (11,16). Perhaps resulting from improved supportive care, mortality in NMS is declining overall: from $76 \%$ prior to 1970 to $11 \%$ in a 1989 study, $(2,11,17)$.

\section{Treatment}

If NMS is suspected, immediately discontinue all antipsychotic medication, as well as other D2 blocking agents. A medical work-up should be initiated (see above): NMS is a diagnosis of exclusion. Supportive care is the mainstay of treatment for NMS and it should occur in a setting in which blood pressure, cardiac rhythm, and pulse-oximetry can be continuously monitored. Autonomic instability may manifest as hypertension, hypotension, tachycardia, or cardiac arrhythmia. Chest wall rigidity can compromise respiration sufficiently to require 
intubation; intubation may also be indicated for severe aspiration pneumonia. Urine alkalinization and adequate support with intravenous fluids may prevent renal failure from myoglobinuria (18). Hyperthermia may require a cooling blanket. Because hyperthermia in NMS is not mediated by pyrogens, antipyretic medications are generally not helpful (1). Laryngeal dystonia, dysphagia, respiratory distress, or delirium may preclude oral intake, so intravenous fluid and parenteral nutrition may be needed (1). Prophylactic measures for deep venous thrombosis and frequent repositioning will decrease the likelihood of complications from rigidity and prolonged immobility (5). The medication list should be reviewed: anticholinergic agents or other drugs that interfere with heat dissipation should be discontinued (1).

Medication may hasten response to supportive therapy and decrease mortality $(19,20)$, but controlled clinical trials do not exist, and drug studies that are available have not always shown benefit (21). The two most commonly used pharmacologic interventions are bromocriptine, a central dopamine agonist, and dantrolene, which facilitates skeletal muscle relaxation via calcium release from the sarcoplasmic reticulum $(5,9,22)$. Dantrolene is available in a parenteral form; bromocriptine can only be administered orally. Symptoms of NMS sometimes return if treatment is discontinued before complete clearance of the offending medication, so, if bromocriptine, dantrolene, or both are utilized, treatment should be continued for ten days beyond the resolution of symptoms, or for 2-3 weeks if the offending agent has been an extended release depot antipsychotic (5).

Oral or intravenous benzodiazepine, the mainstay of early treatment of catatonia, may decrease fever and rigidity in NMS, in addition to treating agitation (1). Respiratory status should be monitored. Positive results have been reported with diazepam (23) and lorazepam (24).

Electroconvulsive therapy (ECT) is another treatment option and may decrease hyperpyrexia, diaphoresis, and delirium, possibly by modulating dopamine activity in the brain. Onset of response, on average, is after 4 treatments (12). ECT should be considered especially for patients who have not improved after 48 hours of pharmacologic treatment, if it is not clear whether the cause of the symptoms is neuroleptic malignant syndrome or malignant catatonia, and if the underlying psychiatric diagnosis is a mood disorder $(12,25-28)$.

\section{Antipsychotic treatment after NMS}

Patients with a history of NMS are likely to require future antipsychotic treatment. The estimated risk of developing NMS again with repeat exposure to a D2 blocker is $30 \%$, and the risk of mortality from subsequent NMS episodes is estimated to be as high as 20\%) (13). Treatment decisions are further complicated 
by the observation that not all patients will experience a recurrence, even if they are treated with the same drug.

There are very few formal studies documenting the outcome of antipsychotic treatment after NMS. Several reviews of this topic were written in the late 1980s (28-30, 32). For example, Olmstead reviewed 29 rechallenges reported in the literature; 13 of the 29 had a recurrence, and 2 of those patients died; the most common agent used for rechallenge was the low potency agent thioridazine (13 of 29 patients, causing 2 recurrences of NMS, one culminating in death) (29). Rechallenges that produce recurrence of NMS are reported with a variety of medications. Rechallenge at least 2 weeks after the initial episode appears to be safer, and recurrence is more likely if high potency medication or high doses are used (1). In a 1989 review, Rosebush and colleagues report that 13 of 15 patients with prior NMS experienced no recurrence on rechallenge (30). And two small, longer-term reviews found that in a majority of patients who are rechallenged with antipsychotic medication NMS does not recur $(31,32)$.

Based on these reviews, on the observed risk factors for NMS, and on theoretical speculation about pathogenesis, we come to the following as recommendations for reinstituting treatment after the first episode, with the understanding that the evidence supporting them is limited. Weigh risks, benefits, and alternatives to antipsychotic medication. If alternatives are poor and the benefit outweighs the risk, restart antipsychotic after a 4-week waiting period following the resolution of the episode. Begin with a low dose, advance slowly toward the target dose, and choose an agent with low D2-nigrostriatal affinity (an atypical or a low potency typical). Monitor carefully for fever, autonomic instability, mental status change, extrapyramidal symptoms, and dehydration. Serial measurements of white blood cell count and CK are warranted. Agitation should be treated aggressively with benzodiazepine, since agitation increases the risk for NMS. Adjunctive treatment with a mood stabilizer, antidepressant, or both for affective symptoms may minimize, possibly, the required dose of antipsychotic $(22,29,33)$. Velamoor has suggested considering prophylaxis with amantadine or bromocriptine (22).

\section{SOURCE INFORMATION}

From the University of Massachusetts Medical School, Department of Psychiatry, Worcester, MA (SG) and the Hospital Traumatologico y Quirurgico Prof. Juan Bosch El Pino, La Vega, Dominican Republic (RP). Address queries to Dr Guzofski: guzofsks@ummhc.org. 


\section{REFERENCES}

1. Susman VL. Clinical management of neuroleptic malignant syndrome. Psychiatry Q 2001; 72:325-336

2. Ananth J, Parameswaran S, Gunatilake S, Burgoyne K, Sidhom T. Neuroleptic malignant syndrome and atypical antipsychotic drugs. J Clin Psychiatry 2004; 65:464-470

3. Berardi D, Amore M, Keck PE,Jr, Troia M, Dell'Atti M. Clinical and pharmacologic risk factors for neuroleptic malignant syndrome: A case-control study. Biol Psychiatry 1998; 44:748-754

4. Khan M, Farver D. Recognition, assessment and management of neuroleptic malignant syndrome. South Dakota J Med 2000; 53:395-400

5. Bhanushali MJ, Tuite PJ. The evaluation and management of patients with neuroleptic malignant syndrome. Neurol Clin 2004; 22:389-411

6. American Psychiatric Association. Diagnostic and Statistical Manual, Fourth Edition (Text Revision) 2000

7. Fink M. Neuroleptic malignant syndrome and catatonia: One entity or two? Biol Psychiatry 1996; 39:1-4

8. Sachdev P, Mason C, Hadzi-Pavlovic D. Case-control study of neuroleptic malignant syndrome. Am J Psychiatry 1997; 154:1156-1158

9. Pelonero AL, Levenson JL, Silverman JJ. Neuroleptic therapy following neuroleptic malignant syndrome. Psychosomatics 1985; 26:946-947

10. Velamoor VR. Neuroleptic malignant syndrome. recognition, prevention and management. Drug Safety 1998; 19:73-82

11. Adnet P, Lestavel P, Krivosic-Horber R. Neuroleptic malignant syndrome. Br J Anaesth 2000; 85:129-135

12. Trollor JN, Sachdev PS. Electroconvulsive treatment of neuroleptic malignant syndrome: A review and report of cases. Aust N Z J Psychiatry 1999; 33:650-659

13. Caroff SN. Neuroleptic malignant syndrome: Still a risk but which patients may be in danger? Current Reviews in Psychiatry 2003; 12

14. Sachdev P, Kruk J, Kneebone M, Kissane D. Clozapine-induced neuroleptic malignant syndrome: Review and report of new cases. J Clin Psychopharmacol 1995; 15:365-371 
15. Karagianis JL, Phillips LC, Hogan KP, LeDrew KK. Clozapine-associated neuroleptic malignant syndrome: Two new cases and a review of the literature. Ann Pharmacother 1999; 33:623-630

16. Caroff SN, Mann SC. Neuroleptic malignant syndrome. Med Clin North Am 1993; 77:185-202

17. Lappa A, Podesta M, Capelli O, Castagna A, Di Placido G, Alampi D, Semeraro F. Successful treatment of a complicated case of neuroleptic malignant syndrome. Intensive Care Med 2002; 28:976-977

18. Lappa A, Podesta M, Capelli O, Castagna A, Di Placido G, Alampi D, Semeraro F. Successful treatment of a complicated case of neuroleptic malignant syndrome. Intensive Care Med 2002; 28:976-977

19. Rosenberg MR, Green M. Neuroleptic malignant syndrome. review of response to therapy. Arch Intern Med 1989; 149:1927-1931

20. Sakkas P, Davis JM, Janicak PG, Wang ZY. Drug treatment of the neuroleptic malignant syndrome. Psychopharmacol Bull 1991; 27:381-384

21. Rosebush PI, Stewart T, Mazurek MF. The treatment of neuroleptic malignant syndrome. are dantrolene and bromocriptine useful adjuncts to supportive care? $\mathrm{Br}$ J Psychiatry 1991; 159:709-712

22. Velamoor VR. Neuroleptic malignant syndrome. recognition, prevention and management. Drug Safety 1998; 19:73-82

23. Kumar V. A case of neuroleptic malignant syndrome treated with diazepam. Can J Psychiatry 1987; 32:815-816

24. Woodbury MM, Woodbury MA. Neuroleptic-induced catatonia as a stage in the progression toward neuroleptic malignant syndrome. J Am Acad Child Adolesc Psychiatry 1992; 31:1161-1164

25. Caroff SN, Mann SC, Keck PE,Jr. Specific treatment of the neuroleptic malignant syndrome. Biol Psychiatry 1998; 44:378-381

26. Davis JM, Janicak PG, Sakkas P, Gilmore C, Wang Z. Electroconvulsive therapy in the treatment of the neuroleptic malignant syndrome. Convuls Ther 1991; 7:111-120

27. Nisijima K, Ishiguro $T$. Electroconvulsive therapy for the treatment of neuroleptic malignant syndrome with psychotic symptoms: A report of five cases. J ECT 1999; 15:158-163 
28. Susman VL, Addonizio G. Recurrence of neuroleptic malignant syndrome. J Nerv Ment Dis 1988; 176:234-241

29. Olmsted TR. Neuroleptic malignant syndrome: Guidelines for treatment and reinstitution of neuroleptics. South Med J 1988; 81:888-891

30. Rosebush PI, Stewart TD, Gelenberg AJ. Twenty neuroleptic rechallenges after neuroleptic malignant syndrome in 15 patients. J Clin Psychiatry 1989; 50:295-298 31. Pope HG,Jr, Aizley HG, Keck PE,Jr, McElroy SL. Neuroleptic malignant syndrome: Long-term follow-up of 20 cases. J Clin Psychiatry 1991; 52:208-212

32. Levenson JL, Fisher JG. Long-term outcome after neuroleptic malignant syndrome. J Clin Psychiatry 1988; 49:154-156

33. Pelonero AL, Levenson JL, Pandurangi AK. Neuroleptic malignant syndrome: a review. Psychiatr Serv 1998; 49:1163-1172 